Sự tăng trưởng các kích thước vùng đầu mặt diễn ra liên tục và đều đặn từ 7-9 tuổi, ở nữ có xu hướng tăng trưởng sớm hơn, nhanh hơn ở nam giới khi so sánh giữa nam và nữ ở cùng khoảng tuổi 7-8 tuổi và 8-9 tuổi, ở mỗi loại khớp cắn theo phân loại Angle.

Lời cảm ơn. Trân trọng cảm ơn những đối tượng tự nguyện tham gia nghiên cứu, cảm ơn sự giúp đõ của Ban giám hiệu trường Tiểu học Liên Ninh, Thanh Trì, Hà Nội. Xin chân thành cảm ơn Viện Răng Hàm Mặt - Đại học Y Hà Nội đã tạo điều kiện cho chúng tôi hoàn thành nghiên cứu này.

\section{TÀI LIẸU THAM KHẢO}

1. Farhad.B Naini (2011). Facial aesthetics: Concepts and Clinnical diagnosis, John Wiley \& Sons Ltd, Chichester, chapter 2, 18-44.

2. J.Leon Williams (1920). New classification of human tooth forns with special reference to a new system of artificial teeth, The dentist's supply .Co, NewYork, 49-124.

3. Ibrahimagic.L, Jerolimov.V, Celebie.A et al (2001). Ralationship between the face and the tooth form, coll. Antropol, 25(2), 619-626.

4. Lê Đức Lánh (2007). Sự phát triển hình thái đầu mặt của trẻ em Viêt Nam từ 12-15 tuổi. Y học Thành phố Hồ Chí Minh, 11(2), 68-78.

5. Võ Trương Như Ngọc (2010). Nghiên cứu đăc điểm kết câu sọ mặt và đánh giá khuôn mặt hài hòa ở một nhóm người Viêtt tuôii từ 18-25, Luần án tiến sỹ y hơc, Viên Đào Tạo Răng Hàm Mặt- Đại học Y Ha Nội, 4-154.

6. Trương Hoàng Lê Thủy, Nguyễn Thị Kim Anh (2012). Sự thay đổi hình thái vùng mặt ở trẻ em Viêt Nam từ 6 đến 12 tuổi. $Y$ học Thành phố Hồ Chí Minh, 16(2), 69-77.

7. Trânn Tuấn Anh (2016). Nghiên cứu một số đặc điểm hình thái, chỉ số đâu măt ở môt nhóm người Việt độ tuổi từ 18-25 có khớp cắn bình thường và khiôn mặt hài hòa, Luận văn tiến sỹ sinh học, Trường Đại học Y Hà Nội, 63-108.

8. Claman $L$ et al (1990). Standardized portrait photography for dental patients, The American journal of Orthodontics and Dentofacial Orthopedics, 98(3), 197-205.

9. Bishara S. E et al (1995). Changes in facial dimensions assessed from lateral and frontal photographs, methodology, The American journal of Orthodontics and Dentofacial Orthopedics, 108(4), 389-393.

\title{
KHẢO SÁT CƠ CẤU DANH MỤC SẢN PHẨM SẢN XUẤT KINH DOANH CỦA CÔNG TY CỔ PHẦN DƯỢC KHOA, GIAI ĐOAN 2015-2019
}

\section{Nguyễn Thị Song Hà*}

\section{TÓM TẮT}

Mục tiêu nghiên cứu: Khảo sát cơ câu danh mục sản phẩm kinh doanh của Công ty cổ phân Dược Khoa giai đoạn 2015-2019. Đối tượng nghiên cứu: Danh mục sản phẩm và một số kết quả sản xuất kinh doanh của Công ty cổ phần Dược Khoa từ năm 2015 đến hết năm 2019. Phương pháp nghiên cứu: Nghiên cứu mô tả cắt ngang. b Cơ cấu danh mục sản phẩm của Công ty giai đoạn 2015-2019 gồm 4 nhóm sản phẩm: Thuốc, TPBVSK (Thực phẩm bảo vệ sức khỏe), Mỹ phẩm và TTBYT (Trang thiết bị Y tế). Nhóm TPBVSK luôn có số sản phẩm kinh doanh lớn nhất với trên $50 \%$ số sản phẩm kinh doanh hàng năm. Nhóm Thuốc có số sản phẩm kinh doanh đứng thứ 2 với khoảng $20 \%$ sản phẩm hàng năm, nhưng là nhóm chiếm tỷ trọng doanh thu chính với trên $40 \%$ tổng doanh thu sản xuất. Nhóm Mỹ phẩm và TTBYT có sự phát triển mạnh về số lượng sản phẩm kinh doanh và doanh thu qua các năm giai đoạn 2015-2019. Kết luận: Nhóm sản phẩm Thuốc là nhóm chiếm doanh thu chính. Cơ cấu sản phẩm có xu hướng chuyển dịch sang nhóm

*Trường Đại học Dược Hà Nội

Chịu trách nhiệm chính: Nguyễn Thị Song Hà

Email: songhaktd@gmail.com

Ngày nhận bài: 8.3.2021

Ngày phản biện khoa học: 27.4.2021

Ngày duyệt băi: 11.5.2021 sản phẩm TPBVSK và nhóm sản phẩm Mỹ phẩm. Tư khóa: Cơ cấu sản phẩm, Công ty cổ phân Dược khoa.

\section{SUMMARY \\ SURVEY ON THE STRUCTURE OF PRODUCT PORTFOLIO OF DUOC KHOA JOINT STOCK COMPANY IN THE PERIOD 2015-2019}

Objectives: Surveying the structure of product portfolio of Duoc Khoa Joint Stock Company in the period 2015-2019. Subjects: Product portfolio and business performance of Duoc Khoa Joint Stock Company from 2015 to the end of 2019. Methods: Cross-sectional descriptive study. Results: The Company's product portfolio in the period of 20152019 included 4 product groups: Drugs, Dietary Supplements, Cosmetics and Medical Equipment. The group of Dietary Supplements always accounted for the highest number of products with more than $50 \%$ of products annually. The group of Drugs possessed the second highest number of products with about $20 \%$ of annual products, however, it accounted for the main revenue with more than $40 \%$ of total revenue. The Cosmetics and Medical equipment group experienced a strong growth in the number of products and sales in the period of 2015- 2019. Conclusion: Drugs account for the main revenue of the company. The product portfolio structure tends to shift to Dietary Supplements and Cosmetics. 
Keywords: Structure of product portfolio, Duoc Khoa Joint Stock Company

\section{I. ĐẶT VẤN ĐỀ}

Cơ cấu danh mục sản phẩm sản xuất kinh doanh của mỗi doanh nghiệp thể hiện được kích thước của tập hợp sản phẩm mà doanh nghiệp đưa ra thị trường và cấu trúc bên trong của tập hợp sản phẩm đó. Cơ cấu danh mục sản phẩm vừa thể hiện thế mạnh của mỗi doanh nghiệp đồng thời cũng thể hiện phản ứng của doanh nghiệp trước những sự biến động của thị trường. Chiến lược về cơ cấu sản phẩm góp phân quan trọng trong sự phát triển của mỗi doanh nghiệp.

Nghiên cứu này nhằm đánh giá sự thay đổi của cơ cấu sản phẩm sản xuất kinh doanh của

\section{KẾT QUẢ NGHIÊN CỨU}

Cớ cấu sản phẩm của Công ty cổ phân Dược khoa giai đoạn 2015-2019

Bảng 1: Cơ cấu số khoản mục sản phẩm của Công ty

\begin{tabular}{|c|c|c|c|c|c|c|}
\hline Chỉ tiếu & $\mathbf{2 0 1 5}$ & $\mathbf{2 0 1 6}$ & $\mathbf{2 0 1 7}$ & $\mathbf{2 0 1 8}$ & $\mathbf{2 0 1 9}$ & $\mathbf{2 0 1 5 - 2 0 1 9}$ \\
\hline Thuốc & 19 & 18 & 20 & 19 & 22 & 25 \\
\hline TPBVSK & 57 & 46 & 53 & 72 & 63 & 145 \\
\hline Mỹ phấm & 4 & 6 & 2 & 8 & 11 & 14 \\
\hline TTBYT & 11 & 5 & 7 & 14 & 22 & 37 \\
\hline Tống & $\mathbf{9 1}$ & $\mathbf{7 5}$ & $\mathbf{8 2}$ & $\mathbf{1 1 3}$ & $\mathbf{1 1 8}$ & $\mathbf{2 2 1}$ \\
\hline
\end{tabular}

Nhận xét: Số sản phẩm sản xuất thuộc nhóm TPBVSK hàng năm là lớn nhất, đồng thời số sản phẩm giai đoạn 2015-2019 cũng lớn nhất. Nhóm Thuốc có số sản phẩm ổn định qua từng năm. Nhóm Mỹ phẩm có số sản phẩm sản xuất hàng năm và giai đoạn 2015-2019 là nhỏ nhất.

Bảng 2: Cơ cấu doanh thu theo các nhóm sản phẩm (triệu đồng)

\begin{tabular}{|c|c|c|c|c|c|c|}
\hline Chỉ tiêu & 2015 & 2016 & 2017 & 2018 & 2019 & Tống \\
\hline Thuốc & 15215,0 & 17594,5 & 21564,2 & 27699,7 & 26651,2 & 108724,7 \\
\hline Tỷ lệ (\%) & 51,8 & 61,3 & 67,7 & 52,5 & 43,9 & 53,5 \\
\hline TPBVSK & 12261,0 & 10312,2 & 8749,2 & 13495,4 & 11511,4 & 56329,2 \\
\hline Tỷ lệ (\%) & 41,7 & 35,9 & 27,5 & 25,6 & 19,0 & 27,7 \\
\hline Mỹ phấm & 639,5 & 403,6 & 810,5 & 9014,0 & 17389,1 & 28256,8 \\
\hline Tý lệ (\%) & 2,2 & 1,4 & 2,5 & 17,1 & & 13,9 \\
\hline Chì tiêu & 2015 & 2016 & 2017 & 2018 & 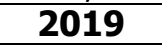 & Tống \\
\hline TTBYT & 1257,1 & 415,4 & 747,3 & 2525,7 & 5111,0 & 10056,5 \\
\hline Tỷ lệ (\%) & 4,3 & 1,4 & 2,3 & 4,8 & 8,4 & 4,9 \\
\hline Tống & 29372,6 & 28725,7 & 31871,3 & 52734,7 & 60662,7 & 203367,1 \\
\hline
\end{tabular}

Nhận xét: Nhóm sản phấm Thuốc có doanh thu hàng năm và doanh thu tống 5 năm lớn nhất (luôn trên $40 \%$ tổng doanh thu), nhóm TTBYT có doanh thu thấp nhất. Nhóm Mỹ phẩm có doanh thu tổng 5 năm đứng thứ 3, nhưng doanh thu có xu hướng tăng mạnh qua mỗi năm và năm 2019 đã vượt nhóm TPBVSK.

Cớ cấu sản phẩm Thuốc theo nhóm tác dụng dược lý giai đoạn 2015-2019

Bảng 3: Doanh thu sản phẩm Thuốc theo nhóm tác dụng dược lý (tỷ đồng)

\begin{tabular}{|c|c|c|c|c|c|c|}
\hline Nhóm thuốc & 2015 & 2016 & 2017 & 2018 & 2019 & 2015-2019 \\
\hline Thuốc điêu trị nghẹt mũi & 9,7 & 10,1 & 11,3 & 15,6 & 11,5 & 58,2 \\
\hline Tỷ lệ (\%) & 63,8 & 57,2 & 52,3 & 56,4 & 43,1 & 53,5 \\
\hline $\begin{array}{l}\text { Thuốc điêu trị nhiếm khuấn mắt, tai có } \\
\text { chứa Corticoids }\end{array}$ & 0,9 & 1,4 & 2,0 & 2,3 & 2,0 & 8,6 \\
\hline Tỷ lệ (\%) & 6,2 & 8,0 & 9,2 & 8,2 & 7,4 & 7,9 \\
\hline $\begin{array}{l}\text { Thuốc điều trị nhiếm khuẩn mắt không } \\
\text { chứa Corticoids }\end{array}$ & 1,0 & 1,0 & 2,2 & 1,8 & 0,9 & 6,9 \\
\hline
\end{tabular}




\begin{tabular}{|c|c|c|c|c|c|c|}
\hline Tỷ lệ (\%) & 6,6 & 5,4 & 10,2 & 6,6 & 3,4 & 6,3 \\
\hline $\begin{array}{c}\text { Thuốc điều trị nhiếm khuẩn mắt có chứa } \\
\text { Corticoids }\end{array}$ & $\mathbf{1 , 7}$ & $\mathbf{1 , 8}$ & $\mathbf{2 , 6}$ & $\mathbf{3 , 6}$ & $\mathbf{3 , 4}$ & $\mathbf{1 3 , 2}$ \\
\hline Tỷ lệ (\%) & 11,2 & 10,5 & 12,1 & 12,8 & 12,9 & 12,1 \\
\hline Thuốc nhỏ mắt khác & $\mathbf{1 , 8}$ & $\mathbf{3 , 3}$ & $\mathbf{3 , 5}$ & $\mathbf{4 , 4}$ & $\mathbf{8 , 8}$ & $\mathbf{2 1 , 9}$ \\
\hline Tỷ lệ (\%) & 12,1 & 18,9 & 16,2 & 16,0 & 33,1 & 20,2 \\
\hline Tổng & $\mathbf{1 5 , 2}$ & $\mathbf{1 7 , 6}$ & $\mathbf{2 1 , 6}$ & $\mathbf{2 7 , 7}$ & $\mathbf{2 6 , 7}$ & $\mathbf{1 0 8 , 7}$ \\
\hline
\end{tabular}

Nhận xét: Doanh thu nhóm thuốc điêuu trị nghẹt mũi chiếm tỷ lệ lớn nhất với 53,5\%; Nhóm thuốc điều trị nhiễm khuẩn mắt không chứa Corticoids chiếm tỷ lệ nhỏ nhất với 6,3\%; Nhóm thuốc nhỏ mắt khác tăng trưởng doanh thu qua các năm và tăng trưởng mạnh doanh thu trong năm 2019 . Các nhóm thuốc còn lại đều sụt giảm doanh thu trong năm 2019.

Cơ cấu nhóm sản phẩm Thực phẩm bảo vệ sức khỏe theo dạng bào chế

Bảng 4. Cơ cấu số khoản mục theo dạng bào chếnhóm sản phẩm TPBVSK

\begin{tabular}{|c|c|c|c|c|c|c|}
\hline Dạng bào chế & $\mathbf{2 0 1 5}$ & $\mathbf{2 0 1 6}$ & $\mathbf{2 0 1 7}$ & $\mathbf{2 0 1 8}$ & $\mathbf{2 0 1 9}$ & $\mathbf{2 0 1 5 - 2 0 1 9}$ \\
\hline Cốm & 4 & 5 & 6 & 10 & 8 & 17 \\
\hline Viên & 27 & 22 & 25 & 30 & 24 & 72 \\
\hline Siro & 26 & 19 & 22 & 31 & 31 & 56 \\
\hline Tống & $\mathbf{5 7}$ & $\mathbf{4 6}$ & $\mathbf{5 3}$ & $\mathbf{7 1}$ & $\mathbf{6 3}$ & $\mathbf{1 4 5}$ \\
\hline
\end{tabular}

Nhận xét: Số khoản mục sản phấm của nhóm sản phấm TPBVSK và mồi dạng bào chế thuộc nhóm này tăng giảm không đều qua các năm. Dạng viên luôn có số khoản mục cao nhất.

Phân tích 10 sản phẩm có tổng doanh thu cao nhất trong giai đoạn 2015-2019

Bảng 5. Mười 10 sản phẩm có doanh thu cao nhất (triệu đđồng)

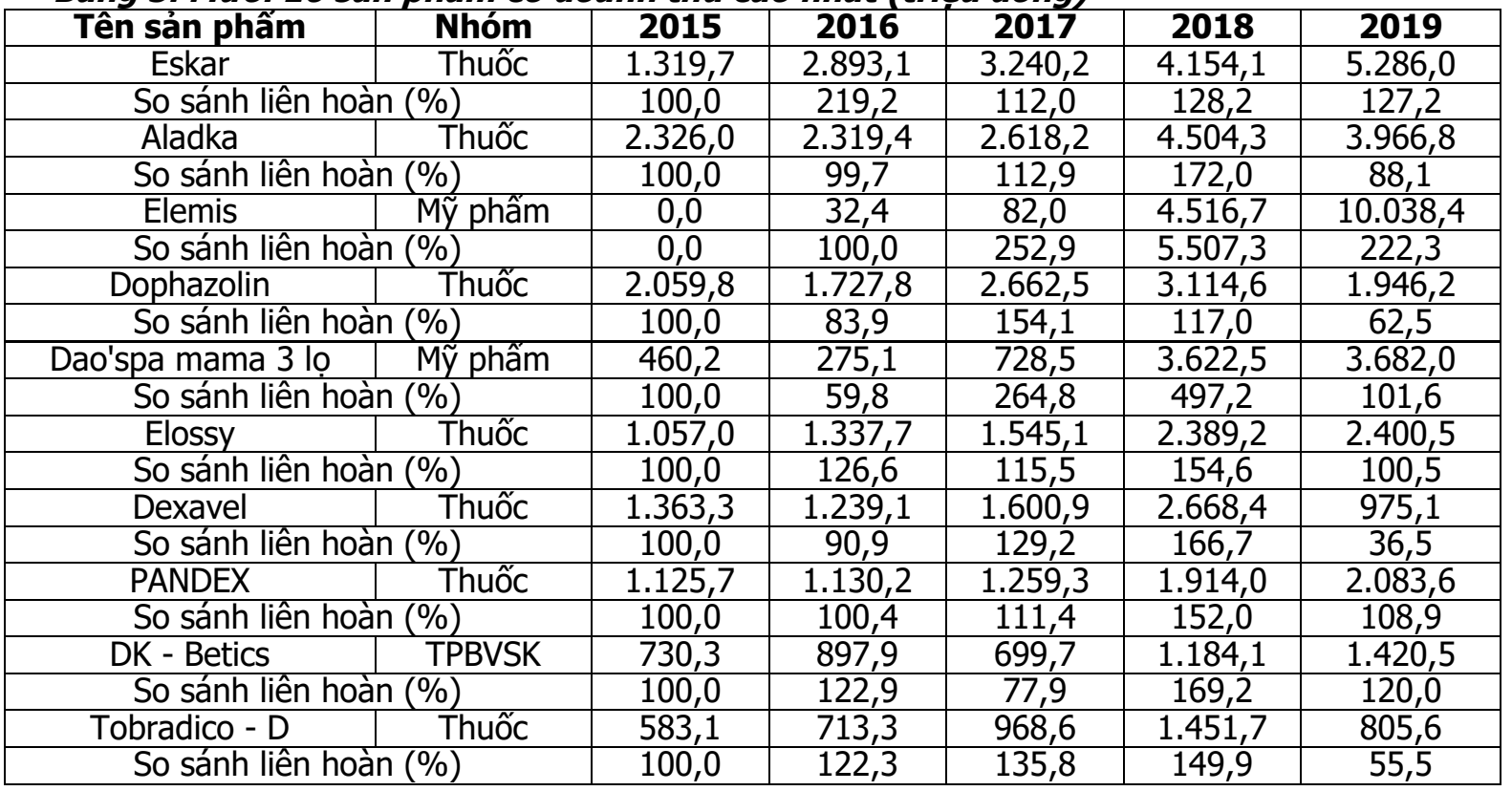

Nhân xét: Trong 10 sản phẩm thì có 7 sản phẩm là thuốc, 2 sản phẩm là mỹ phẩm và 1 sản phẩm thuộc nhóm TPBVSK. Trong đó 3 sản phẩm là Éskar (Thuốc), Elemis (Mỹ phẩm) và DKBetics (TPBVSK) giữ được mức tăng trưởng trên $10 \%$ trong năm 2019. Sản phẩm Elemis có tốc độ tăng trưởng mạnh nhất, một số sản phẩm tăng trưởng âm trong năm 2019.

\section{BÀN LUÂ̂N}

Danh mục sản phẩm kinh doanh của Công ty cổ phần Dược khoa giai đoạn 2015-2019 gồm
221 khoản mục, nhóm Thực phẩm bảo vê sức khỏe luôn có số khoản mục lớn nhất nhưng doanh thu chỉ đứng thứ 2 sau nhóm Thuốc. Danh mục sản phẩm của Công ty có số lượng không ổn định qua các năm, trong đó nhóm sản phẩm TPBVSK có biến động về số khoản mục lớn nhất. Nhóm sản phẩm TPBVSK được dự báo có khả năng phát triển tốt ở thị trường Việt Nam trong giai đoạn nghiên cứu. Lãnh đạo của Công ty đã rất kỳ vọng và có những chiển lược nhất định nhằm phát sự phát triển của nhóm sản 
phẩm này, thể hiện qua việc đầu tư xây dựng xưởng GMP-TPBVSK. Tuy nhiên dữ liệu về doanh thu của nhóm sản phẩm này chỉ đứng thứ 2 trong 4 nhóm, chiếm 27,7\%. Doanh thu của nhóm TPBVSK tăng giảm không đều qua các năm. Trước tình hình đó, Doanh nghiệp cần có những chiến lược tốt hơn đễ phát triển nhóm sản phẩm này, cần tăng cường phát triển các sản phẩm tương tự DKBetic (sản phẩm nằm trong nhóm 10 sản phẩm có tổng doanh thu cao nhất trong 5 năm 2015-2019 đồng thời giữ được mức tăng trưởng trên 10\% trong năm 2019).

Trong 4 nhóm sản phẩm được sản xuất tại Công ty, nhóm sản phẩm Thuốc luôn là nhóm sản phẩm chiếm tỷ trọng chính về doanh thu. Lãnh đạo công ty đã có những đầu tư cho nhóm sản phẩm này như tiến hành nâng cấp dây chuyền sản xuất dung dịch thuốc mắt mũi, đã đâu tư thêm dây chuyền thuốc hỗn dịch vô trùng và dây truyền thuốc nước uống dạng lỏng. Số khoản mục của nhóm Thuốc ổn định trong giai đoạn 2015-2019. Trong 10 sản phẩm có tổng doanh thu cao nhất thì có tới 7 sản phẩm thuộc nhóm thuốc. Những điều này cũng thể hiện được tầm quan trọng của nhóm sản phẩm Thuốc trong cơ cấu sản phẩm kinh doanh của công ty. Tuy nhiên, qua phân tích cơ cấu sản phẩm nhóm Thuốc cũng cho thấy một số điểm chưa hợp lý thể hiện qua sự sụt giảm doanh thu trong năm 2019. 6 sản phẩm thuốc có doanh thu cao nhất không có được sự tăng trưởng hoăc tăng trưởng âm trong năm 2019, chỉ có sản phẩm Eskar (hoạt chất là Sodium chloride) giữ được sự tăng trưởng.

Phân tích cơ cấu Thuốc theo nhóm tác dụng dược lý cũng cho thấy sự sụt giảm về doanh thu, chỉ có nhóm thuốc nhỏ mắt khác (chứa thành phần hoạt chất là Sodium chloride) có mức tăng trưởng 198,0\% trong năm 2019. Lãnh đạo công ty cũng bắt đầu có những chiến lược cho nhóm sản phẩm này: nghiên cứu phát triển và đưa vào sản xuất các sản phẩm mới (Tobeta, Neobeta, Cipmedic...); phát triển các dạng bào chế mới (hỗn dịch thuốc mắt, mũi; dung dịch thuốc nước uống; hỗn dịch thuốc nước uống); phát triển các sản phẩm có thị trường rộng lớn (nhóm sản phẩm thuốc nhỏ mắt có chứa Sodium Chloride, nước mắt nhân tạo), tuy nhiên tiến độ triển khai và kết quả không được như kỳ vọng. Đầu năm 2020 công ty đã tiến hành sản xuất một số sản phẩm thuốc ở các dạng bào chế khác: Wizoson, DKSolon (hỗn dịch thuốc xịt mũi); DKCetamol (Hỗn dịch uống); Desloratadin (Dung dịch uống).

Nhóm sản phẩm Mỹ phẩm và nhóm TTBYT thể hiện được sự tăng trưởng mạnh mẽ trong 5 năm giai đoạn 2015- 2019. Năm 2019, nhóm này có doanh thu vượt nhóm TPBVSK và chiếm $28,7 \%$ tổng doanh thu chỉ với 11 sản phẩm kinh doanh. Trong nhóm Mỹ phẩm có 2 sản phẩm đặc biệt là Dao'spa mama và sản phẩm Elemis (Dòng nước tắm dành cho mẹ và bé) có sự tăng trưởng mạnh và doanh thu cao trong giai đoạn 2015-2019, cả 2 sản phẩm này đều nằm trong 10 sản phẩm có doanh thu cao nhất trong giai đoạn 2015-2019. Điều này cho thấy Công ty đã có những chiến lược tốt cho nhóm sản phẩm Mỹ phẩm. Song song với 2 sản phẩm trên, công ty cũng đã triển khai bộ các sản phẩm mỹ phẩm dành cho me và bé (Yaocare mama, Yaocare mama gel, Yaocare baby, Yaocare baby Plus) và cũng cho thấy xu hướng phát triển tương đối tốt.

\section{KẾT LUÂ̂N}

Qua phẩn tích cơ cấu sản phẩm kinh doanh của Công ty cổ phần Dược khoa cho thây Thuốc là nhóm chiếm doanh thu chủ yếu (khoảng $50 \%$ tổng doanh thu sản xuất các năm). Trong danh mục sản phẩm nhóm thuốc, hầu hết không phải là thuốc điều trị thiết yếu và dần chuyển sang dòng sản phẩm nhỏ mắt chứa thành phần Sodium chloride và nước mắt nhân tạo.

Chiến lược của Công ty thể hiện rõ việc chuyển dịch cơ cấu sản phẩm sang nhóm sản phẩm TPBVSK và nhóm sản phẩm Mỹ phẩm, điêuu này phù hợp với xu hướng và quy mô doanh nghiệp trong giai đoạn này. Sản lượng và doanh thu của nhóm Mỹ phẩm có sự tăng trưởng mạnh, đến năm 2019 doanh thu chỉ đứng sau nhóm Thuốc. Các sản phẩm Mỹ phẩm tập trung chủ yếu vào nhóm sản phẩm cho mẹ và bé, trong đó có sản phẩm Elemis có doanh thu cao nhất trong các mặt hàng sản xuất trong năm 2019.

\section{TÀI LIỆ THAM KHẢO}

1. Bộ môn Quản lý \& Kinh tế dược (2007), Giáo trinh quản lý và Kinh tế Dược, NXB Y học, Hà Nội.

2. KIS (2019), "Báo cáo ngành 09/01/2019 - Triển vong ngành Dược Việt Nam".

3. Lề Văn Tâm, Trân Hoàng Kim (1994), "Chiến lược kinh doanh, phương án sản phẩm lựa chọn và qưyết định", NXB Thống Kê, Hà Nội.

4. Lê Văn Tấm (2000), "Giáo trình quản trị chiến lược", NXB Thống Kề, Hà Nội.

5. VietŃam report (2018), "Các xu hướng lợi nhuận theo ngành kinh tế năm 2018-2019".

6. Antonio Angelino, Do Ta Khanh, Nguyen An Ha, Tuan Pham (2017), "Pharmaceutical Industry in Vietnam: Sluggish Sector in a Growing Market", International Journal of Environmental Research and Public Health. 